\title{
Feminist Interventions in Electronic Environments
}

\author{
MARY E. HOCKS \\ Georgia State University
}

\begin{abstract}
Recent feminist cultural studies of technology analyze how discourses and practices that circulate in high-tech culture reproduce and enact the same unequal power relations embedded in our institutions and day-to-day activities. Feminist interventions are communicative acts that bring aftention to the shifting power relations within a specific discursive context. An analysis of the assumptions about audience that operate in electronic artifacts demonstrates how power relations play out within particular communities. The author argues that enacting feminist interventions in online environments changes the online community's identity and sense of audience, and that creating feminist multimedia can help ensure a more human, diverse and gender balanced human presence in all forms of technology and new media.
\end{abstract}

community electronic conferences feminist critiques of technology intervention multimedia

The publication of "Women and Computers: An Introduction" in the 1990 special issue of Signs signaled that the mainstream women's studies movement had become aware of the troubled relationship between computer technology and gender because of how technologies both reflect and play a role in historical sexism and cultural politics (Perry \& Greber, 1990). Recent feminist cultural studies of technology specifically analyzed how discourses and practices that circulate in high-tech culture reproduce and enact the same unequal power relations embedded in our institutions and day-to-day activities. As Anne Balsamo (in press) has argued, "all technologies reproduce cultural arrangements. In this sense, all technologies are reproductive technologies." Similarly, scholars in composition studies have argued that computer technologies both reflect and affect cultural ideologies such as class divisions and gender inequality (Kaplan, 1991; Selfe \& Meyer, 1991; Selfe \& Selfe, 1994). Researchers in several disciplines have thus demonstrated that computer technologies can never be neutral: They are completely embedded in cultural processes.

Feminists first pointed out that new technologies tend to affect women's professional lives negatively and to provoke shifts in the divisions of labor that perpetuate male privilege (Hacker, 1989; Kramarae, 1988). Technology often inspires what Jennifer Terry and Melodie Calvert (1997) called "positivist narratives of technological mastery of Man over nature" (p. 2). However, too often, technological development benefits a select few and simply incorporates the international exploitation of labor, natural resources, the environment, and working class women. Studies have documented the persistence of sexism on

Direct all correspondence to: Mary E. Hocks, Georgia State University, Department of English, University Plaza, 38 Peachtree Center Avenue, Atlanta, GA 30303-4038. E-mail: <mhocks@gdu.edu>. 
the Internet, in spite of women's increased presence and their creative responses to online harassment (Brail, 1996; Kramarae \& Taylor, 1993; Spender, 1995; Sullivan, 1997). Feminist critiques of scientific practice demonstrated how cultural ideology and perceived historical fact are mutually reinforcing, resulting in the masculinizing of science and technology, the privileging of those masculine values, and the exclusion of women's work from valued scientific practice (Harding, 1986; Hubbard, 1989; Keller, 1985; Perry \& Greber, 1990). Evelyn Fox Keller (1985) described these circular processes that reinforce masculine-coded scientific ideas and simultaneously devalue or erase other ways of knowing. Other scholars have argued that feminine perspectives can offer alternate, more holistic ways of knowing, including collaborative social processes for constructing facts and new relationships to objects of study that privilege identification rather than objectification (see, e.g., Harding, 1986). The social processes that underlie scientific knowledge-making, however, are considered outside the realm of scientific methods and objectivity and are therefore undermined by definition. These critiques of science and technology, although operating with different assumptions about cultural politics, have firmly established how gender is intimately connected to the ways new technologies are developed, represented, and valued in our culture.

Feminist cultural studies have focused on the politics and practices of representation in science and technology in relation to the female body, highlighting how women's bodies are manipulated, obscured, or fundamentally changed by technological environments and the discourses of new technologies (Balsamo, 1995; Haraway, 1991; Martin, 1992; Wajcman, 1991). Allucquere Rosanne Stone (1991), for example, demonstrated how the abstract concept of cyberspace, while allowing for identity playfulness, also obscures the physical body:

\footnotetext{
The discourse of visionary virtual world builders is rife with images of imaginable bodies, freed from the constraints that flesh imposes. Cyberspace developers foresee a time when they will be able to forget about the body. But it is important to remember that virtual community originates in, and must return to, the physical.... Even in the age of the technosocial subject, life is lived through bodies. (p. 113)
}

This ambivalence about the erasing of the body, and its accompanying social identities, is a fundamental tension in discussions of virtual environments. Positioning specific bodies and their accompanying identities within technological discourses and practices becomes a powerful means for political action, for resistance, and for social change. Virtual technologies create an appearance of escape from many aspects of the physical body, but our hearts and our minds tell us those bodies still matter. Physical death is an extreme reminder of how transitory are virtual identities and freedoms. Michael Joyce (in press) eloquently described his experience with these tensions and loss in a MOO space where he encountered in words the presence of its creator Anne Johnstone, who had died in 1995. His elegiac exploration pointed to the illusions of coherence and presence through words in electronic spaces that, like memories, continue to exist after the body has passed away. This ambivalence about both escaping and reifying our real bodies and identities in relation to virtual environments, I believe, marks a fundamental characteristic of electronic environments and becomes the site where feminist interventions make a difference.

To illustrate how technologies reproduce cultural arrangements, I examine several CD-ROM designs and an electronic discussion list in the remainder of this article. Analyzing the assumptions about audience that operate in these artifacts demonstrates how power 
relations play out within particular electronic environments. Feminist interventions in these environments offer solutions for breaking dominant cultural patterns that erase bodies and identities, exclude women, and devalue their contributions in technological areas. By creating feminist software applications and enacting feminist interventions in online environments, we ensure a more humane, diverse, and gender-balanced human presence in all forms of technology and new media.

\section{FEMINIST SOFTWARE AS INTERVENTION}

Feminist Web sites and grrls sites have proliferated on the Internet over the past several years, creating accessible resources for feminist research and activism, as well as images and attitudes that resist the stereotyped images of women as victimized by computer culture (Sherman, 1998; Wakeford, 1997). CD-ROM resources, however, as high end interactive media, are costly and time-consuming to produce. The only example I found of a feminist CD-ROM title is Christine Tamblyn's (1997b) self-published CD-ROM She Likes it, she likes it not, which playfully explored her ambivalent relationship with technology. Titles such as Tamblyn's are not available commercially, however, and are quite difficult to locate. An award-winning CD-ROM by Amnesty International (1994), which included letters, documents, and concert footage, provided a rare example of a title with political goals widely distributed.

In contrast, a large number of commercial software programs are commercially available that focus on violent games and pornography apparently aimed at male audiences. Even a benign and popular computer game such as Tomb Raider Gold (1997) depicts the central character as a sexual object with a bursting bust line. Typical computers games marketed to girls include the Barbie Software for Girls titles Magic Hairstyles, Cool Looks Fashion, and Magic Fairy Tales (published by Mattel Media, 1997). The Learning Company has published the American Girls Premiere, a play-staging game starring their line of dolls that represent stereotypical femininity and traditional values. These titles represent the software available in retail stores marketed specifically to young girls. They aim to capitalize upon the mass market audience of consumers of these dolls. A few CD-ROM titles have countered these trends. The popular Carmen Sandiego titles for children, such as Where in Time is Carmen Sandiego? (1997), included educational information in a gender-neutral way and portrayed strong, intelligent women characters. The Purple Moon Company has developed a Web site and several companion CD titles. These "friendship adventures" like Rockett's Tricky Decision (1997) are aimed at pre-teen girls interested in participating in technological culture in a diverse and collaborative environment. In spite of these efforts, CD-ROM publishing has lagged far behind World Wide Web (WWW) publishing in terms of resisting dominant cultural stereotypes or creating alternatives for women and girls.

Publishing and reviewing software titles and Web resources that reflect women's interests, research, and accomplishments will eventually affect the public perception of software. Just as women writers and musicians have traditionally been ignored or marginalized, when recognized and promoted by the popular press, they become newly visible and audible to a wider audience. Those of us who must develop and publish electronic materials highlight women's accomplishments and experience, their political struggles, and their written, visual, and spoken art. Feminists who design electronic media can 
offset the dominance of titles aimed at males and engender more diverse images of women.

I had these goals in mind when designing a multimedia presentation for the NonGovernmental Organization (NGO) Forum of the United Nations Fourth World Conference on Women, which took place in Beijing, China in September 1995. Created for the international feminist audience attending the conference, "Women of the World Talk Back" used interactive video to document the accomplishments of the United Nations' political conference in defending the rights of women and girls worldwide. As I have written elsewhere, this exhibit became an occasion for an on-going conversation rather than a static presentation to a passive audience (Hocks, in press). By showing this presentation, my collaborators and I set out to enact actual dialogue in visual form about women, science, and technology among the women at the conference. ${ }^{1}$ Our goal was to create a communication experience that brought people together to discuss the key topics of the conference, especially women's experiences with technology. The kiosk-highlighting real voices woven together in video interviews with conference leaders-provoked responses from women activists about the projects in which they were engaged around the world. We talked informally with activists who use traditional media to help women organize and who educate women about their rights. These activists included publishers of women's newsletters from Haiti, TV producers from India, and labor union organizers from Botswana. Their work aimed to politically inform and train women using various media and communications technologies, from faxes to radio broadcasts. In several cases, we videotaped interviews with people who visited the booth about their media-oriented activist work and later incorporated these statements into the final multimedia documentary version of our project. It has been an incredibly rewarding experience to develop collaboratively a professional quality multimedia narrative and now present it to others for continued discussion at conferences and in political forums. Most importantly, the audience for the project has participated in its development and, in some cases, has become literally part of the presentation.

Because this project was developed to document a particular moment in narrative form, our efforts complement the increasing use of the WWW by feminists. The Web site Virtual Sisterhood, for example, promotes electronic networking and communication very effectively within the global women's movement and has collected many sites specifically about the Fourth World Conference as well as about specific NGO's. ${ }^{2}$ In contrast, few published titles can claim to have academic value and an activist role in politics or culture. ${ }^{3}$ The feminist potential for developing different kinds of multimedia for activist or

\footnotetext{
${ }^{1}$ The design team consisted of myself and Communications Professor Anne Balsamo, three graduate students in Georgia Institute of Technology's MA Program in information design and technology, one professional TV producer, and one professional musician. Balsamo and I, the project directors, provided the basic design concept and content for the project. Our planning team included graduate students Kelly Johnson, a multimedia project manager; Mary Anne Stevens, a graphic designer; and David Balcom, a multimedia author. Phil Walker, a TV producer working at the Georgia Tech campus communications division, produced the interviews and the music soundtracks used in the project. With the help of an Atlanta musician, Bryan Arbuckle, Walker cowrote and produced the music used in the project. On recent modules, Sandra Beaudin and Professor Ellen Strain contributed additional graphic design and authoring.
} 
aesthetic purposes is just beginning to be recognized. In our case, to construct a rich multimedia narrative with some sense of closure, we took into account the benefit of particular technologies, which are inevitably in transition. We made use of our institutional privilege to obtain and work with broadcast-quality video resources. With an international feminist audience in mind, we deliberately designed the multimedia project to be attractive, inviting, and simple to use. We incorporated original music, high-quality photographic images of women leaders, and a background screen of a richly-colored quilt. By combining music, video, and graphics with the techniques of documentary film and the interactive quality of multimedia, our project appeals to the senses, and it tells stories with pictures and voices rather than just words.

The rich communicative possibilities of the World Conference setting, combined with the content, helped make this project a successful vehicle for grassroots feminist activism and connection. As a stand-alone multimedia presentation, it is designed specifically to make a feminist statement on topical, visual, and aesthetic levels. By presenting this work (and writing about it) in academic forums, as well as to students in various courses, we are also promoting the importance of making technology integral to a women's studies curriculum. I firmly believe that feminists must create their own audiences and involve them in technology by developing projects in all forms of new media, while continuing to monitor and critique cultural images of gender.

\section{FEMINIST INTERVENTIONS IN ELECTRONIC CONFERENCES}

Because many networked communication forums, such as discussion lists and newsgroups, have been and continue to be dominated by male users, we also need constant feminist participation and activism in networked environments. Creating alternate discourses and network spaces is effective for building visibility and community, but those public spaces remain vulnerable to flaming and invasions by anyone hostile to the group. Internet users sometimes invade social spaces created by females for networking and for interacting along identity lines. For instance, a female student in my writing course last year wrote an investigative paper about an Ebony chatroom in American Online (AOL) devoted to general conversation among black women. A self-identified white male entered the room, provoked an argument with the group, and then sent the student an instant message, which is a personal e-mail that interrupts the user's chatroom activity and appears immediately on the screen. He asked inappropriate sexual questions and harassed her to the point that she felt she could not continue her research. Other students in my course affirmed that these experiences occurred in the black-woman-identified electronic spaces they frequent. This instance of sexism and racism is an example of the harassment

\footnotetext{
${ }^{2}$ Virtual Sisterhood can be found at $<$ http://www.igc.org/vsister/>. The site includes networking opportunities, chat forums, and an online magazine (Women'space) about electronic feminist activity.

${ }^{3}$ My review process consisted primarily of looking in academic collections and academic press advertisements, scanning bookstore shelves, and searching the World Wide Web for CD-ROM publications. I also posted messages and asked colleagues if they knew of any CD-ROMs currently being developed. Because of the number of unpublished applications currently under development. it remains difficult to determine if other applications exist.
} 
that still occurs in women-identified spaces and a weary reminder that electronic landscapes do reproduce at times the outrageous behavior sometimes found in face-to-face social interactions.

Despite these disturbing instances, feminists have documented the resistance to online male territory offered by feminist and grrl electronic spaces on the World Wide Web. As Nina Wakeford (1997) pointed out, we must "be alert to writing [that] ignores alternative discourses of women's experiences in online life, and unthinkingly mirrors the 'moral panics' of widespread media puhlicity" (p. 53). Can a hostile environment-a legal definition of sexual harassment-actually develop on public electronic forums? What exactly is at stake if harassment occurs in a nonwork environment? Stephanie Brail (1996) noted that legal definitions of harassment and public perceptions of online harassment do not match up neatly. Although certain civil laws and criminal laws of defamation and libel do protect internet users, annoying events like receiving unsolicited pornography do not constitute harassment (pp. 149-150). Our online environments might be only as threatening as our face-to-face public environments; these simple reactions to inhospitable environments have a limited effect. Feminist resistance and confrontation, however, can become viable, ongoing strategies for gaining power in the online community.

Networked discussion leads to the creation of a community that is exclusively online but also overlaps with other discourse communities. As Nancy Baym (1995) has demonstrated, one can trace how an electronic community is formed from moment to moment through public discussions, and how that constructed image of community continually includes and overlaps with other discourses-in her example, popular culture and soap opera fan's lives. Electronic forums allow like-minded people with similar interests to congregate and collaborate, with the luxury of ignoring topics or people that don't interest them. The characteristics amplificd by clectronic discussion forums include rapid publishing, flaming, mixing performances of public and private discourses, blurring of writers and audience, and exploiting the possibility of identity and anonymity. These features can actually heighten the level of conflict between different perspectives. On academic electronic discussion lists, for example, discussions have the flavor of professional conferences and academic debates in that they include different perspectives on theory, aesthetics, and broader cultural and political issues surrounding electronic culture. Participants discuss freely in what George Landow (1993) considered a new academic discourse. Landow argued that these electronic forums create democratic space where participants from undergraduate students to published writers operate on equal ground. Thus, a moment of intervention that merely shifts topics appears enjoyable and rather benign. However, I believe these interventions point to precisely the power structures of this communicative social context and to negotiations for meaning and consensus that take place in other arenas of professional academic life. In academic discussion lists, given the spirit of debate and the posturing that inevitably takes place, an intervention marks a power move in the discussion. Far from benign, an intervention is a deliberately political act. Feminist interventions in this context are key moments in which a strategic change of topic and tone precipitates a dramatic change in the communicative context and perception of audience. The disruptive intervention, by drawing explicit focus to issues of audience, realigns the group's sense of community. These communicative acts have the primary aim of shifting and bringing attention to power relations within that specific discursive context. 
Two series of postings by feminists that occurred on the Technoculture (TNC) discussion list in March 1992 and in January 1993 best exemplified this type of feminist intervention. ${ }^{4}$ TNC, an electronic conference with over 300 teachers, students, writers, and scholars participating, was created to discuss the cultural studies of technology in light of an upcoming conference. I focus on two public conversations in which men dominated the conversations and several women made explicitly feminist interventions to illuminate the power relations inherent in the dynamics of the discussions. Because TNC was a public academic discussion forum, participants used their real names and, often, their institutional affiliations. However, in this reading of the discussions, I have decided to keep the writers' names anonymous.

\section{"Dear Boys"}

Three days after the Technoculture discussion list came to be, a long and carefully crafted message entitled "Dear Boys" was posted as a feminist intervention by two participants. After alluding to various definitions of technoculture, which had been a subject of discussion, the message (reproduced in its original format, but edited) read as follows:

Dear Boys. . .

So many questions, so little time. We'll begin with the first one: "What is TNC?"

1) TechNoCulture was, first of all, a casual tossed-off comment by Anne. More to the point, TNC is the handle for a conversation that includes what can only be described as masturbatory e-jaculations of pretty-boy techno-speak.

... [2 paragraphs omitted]

Do you assume the screen is a mirror, reflecting an image of your- self as your ideal reader? What notion of audience is at work here? After reading 20-odd postings, we began to understand that some contributors assumed that their readers would appreciate and endorse gratuitous comments about A. Ross, and Kim Basinger's legs, and disparaging comments about a certain mode of cultural criticism and scholarship. What cultural conditions enable them to make such assumptions about the readers of this list? How can one be so dismissive of the broader social and cultural network within which their network postings make sense? What is the distribution of these clever comments and uninformed criticism? What about the bodies of those who interact through these channels, the cultural identities they embody, and the bodies they are connected to. . (colleagues of A.Ross, future employers, tenure committees)?

... [2 paragraphs omitted]

And since we started with a parlor-game, let us suggest additional questions more in keeping with the topic of this list: What is the difference...

. . between a flame and valid criticism? . . . between posturing and postmodern language games? ... . between electronic writing spaces and the phallacy of the blank page?

And who said feminists have no sense of humor? :-)

(TNC, March 1992)

\footnotetext{
${ }^{4}$ The electronic discussion list Technoculture was co-founded by Anne Balsamo and Stuart Moulthrop at the Georgia Institute of Technology in preparation for an upcoming conference. It began with a welcome message from Stuart A. Moulthrop on Friday, March 13, 1992 and remained active for at least a year. I used only the transcripts from the months mentioned in the text. For copies, e-mail $<$ mhocks@gsu.edu>.

${ }^{5}$ Because it was a public forum in which I participated, I believe I characterize the gender dynamics of the discussion in good confidence. Although I obtained permission from the writers quoted directly, I chose to focus on the dynamics of discussion rather than on individual writers. Note that feminist interventions are often mistakenly remembered and even deliberately distorted after the fact.
} 
This lengthy message was written in response to conversations that took place about cultural critic Andrew Ross. Because of its subject line, "Dear Boys," it read as a friendly nudge-_.'Hey guys, cut it out!" The writers invoke their readers' shared knowledge about academia, postmodern theory, and critiques of technology. The serious tone and careful, pointed critique of participants' assumptions about audience, however, brought the jokes to a halt and initiated a self-reflective turn back onto the conversation. In essence, these women enacted a classic intervention with an acute feminist critique of male-centered postmodernist discourse-what they characterized as the "masturbatory e-jaculations of pretty-boy technospeak." Such an intervention could have easily appeared in print or been spoken in a conference setting, but within an electronic discussion list it has the effect of a dramatic, even angry, interruption and a deliberate change of topic.

The effect of this intervention was that the writers revealed the participants' mixing of public and private modes of discourse, and revealed their narrow perception of audience, by asking "Do you assume the screen is a mirror, reflecting an image of your- self [sic] as your ideal reader?" This description, reminiscent of the imagined audience in Walter Ong's (1975) well-known formulation of audience as a fiction created by the writer, takes on a distinctly self-referential postmodern quality as a narcissistic reflection in a mirror. For any writer, part of understanding audience is getting past that narcissism. As James Porter (1992) described it, "discourse is developed through interaction-it is developed dialogically, through the process of the 'person' moving from speaker role to audience role and back and forth" (p. 81). However, the socially constructed nature of discourse itself complicates the relationship between writers and audiences. One effect of poststructuralist discourse is the blurring of author and audience interactions, which Louise Phelps (1990) characterized by "a more fully contextualized, polyphonic, contentious model of transactionality that encompasses multiple participants and voices along with situation, setting, institutions, and language itself-and finds it hard to maintain firm boundaries between self and other" (p. 156). Partly because the illusions of privacy and solitude that electronic mail fosters, the resulting blurring of private and public discourse can become key features of public electronic forums. This blurring, in turn, is simply a feature of the poststructuralist discourse Mikhail Bakhtin (1986) characterized as an intertextual web of private and public discourses. The fluid boundaries between author and audience point to how easily the image of the virtual audience can be distorted.

The intervention opened up participation by others and immediately expanded the perceived audience of the list. Many other feminists joined the discussion, contributing clarifications and points of agreement, often conveyed in personal language. Several participants, both male and female, characterized the discussion as newly charged with energy. A few days later, the two writers responded with another message about the communicative implications of their rant:

First of all, thanks for taking our rant with appropriate good humor and respect. We're not essentially angry women, but sometimes anger has its place. One of the very interesting aspects of the responses so far is that "the personal" has errupted into a space that was previously saturated with theoretical discussion. This is not a banal point about the "personal is political, or even theoretical," rather we take this "erruption" as an illustration of what it means to talk about "situated communi cation practices." <Intervention=ernuption>

(TNC, March 1992) 
Feminist intervention, identified as an erruption that marks a moment of situated communication practice, provides a strategic method for displacing the dominant conversation and creating reflective practice. It also immediately shifts the perceptions of audience and breaks whatever illusions of privacy and anonymity are operating at the time. Interventions are only temporary, however, as momentary displacement of power dynamics that require repeating. In this first intervention, feminist discussion continued on and off for only another couple of weeks. Many feminists gave up on the conversation and signed off for good.

\section{"Invisible Still"}

The following January, TNC experienced another intervention. A long discussion of computer pornography had ensued that was dominated by several men on the list who continually brought the discussion back to the question of what constitutes pornography in cyberspace. Women on the discussion list either objected to the discussion or denounced it as an uninteresting issue. One feminist argued that certain participants were more interested in "what is pornography" than in real ideological questions of gender and power. A male participant responded that an "insistence on gender. . too often feels like an insistence on one gender rather than on another." The feminist writer then posted a message entitled "Invisible Still," which immediately brought the conversation to a halt:

\footnotetext{
There is, at this moment, a terrible tightness in my chest. My impulse is to wail, or to scream, or to beat my fists against the wall. Why is it that I cannot cannot cannot be SEEN/READ?

I write:

What I find most fascinating/distressing about this discussion is the way that it keeps insistently moving away from questions of gender and power. and back to the contested but not inherently threatening (to men) discussion of "what is pornography? is this? is that?" . . My insistence on the primary importance of issues of gender and power is an intrusion-- a collaring, a "hey, you guys. let's talk about *me* for a minutc." A blank stare; a "huh?" and back to the conversation.
}

(TNC, January 1993)

This intervention, like "Dear Boys," emerged out of a conversation built upon shared theoretical knowledge and academic conversation. It also was deliberately crafted to give the appearance of an angry demand for recognition. These comments successfully turned the conversation into a politicized discussion of the conversation itself. One male participant, immediately defensive, accused the comment of creating "an intolerable discursive situation." Another male participant took offense and wrote that "whether her narrative is triumphant or hysteric, it is out of place. Should we all express gratitude to [her] that it is now appropriate to vent one's spleen in an academic context?" Certain male participants clearly felt personally affronted and attacked by this intervention, but many other participants-male and female-added statements of agreement and support. The intervention rapidly changed the discursive center of the conversation by forcing self-reflection upon the participants.

The writer of "Invisible Still" then produced a long account of the exchanges surrounding the "Invisible Still" post that explains to the list participants how this social network behavior replicates face-to-face confrontations in which men shut out the hysterical reactions of women. She reminded everyone how her disruptive posting was not true conversation, but crafted writing, and calculated to achieve a certain effect: 
I had all the time in the world to compose those lines. What might be read as an outburst might have actually been crafted as careful prose, for effect. . . . Or I might have been truly furious. (TNC, January 1993)

It was obviously a moment of deliberate performance art on the network and an act to invoke a specific subjectivity. Stressing the relationship between language and power, she wrote that the "subject is indeed produced by power, though the relationship between the subject and power is reciprocal, as discourse itself is reciprocal." Another participant, fascinated with the effect this apparent outburst had upon the conversation, noted that speaking or writing this message would be considered inappropriate in many contexts. The written image of an emotionally charged reaction immediately changed the topic of the discussion away from pornography and onto issues of subjectivity, silencing, and exclusion.

These examples demonstrate that, without interventions and confrontations in public forums, feminist concerns are typically not at the surface. Feminist interventions bring attention to particular subjects, the bodies behind the voices that inhabit the electronic space. As Kali Tal (1996) argued, this aggressive discourse represents "bearing witness" to bring the concerns of a marginalized group to the front and center (p. 7). The TNC members still operating with the narrow sense of audience as their own reflection did not always see feminists as part of that audience, which in turn made the interventions appear that much more confrontational to them. Ironically, those participants who found emotionally charged comments inappropriate for a public academic forum did not acknowledge their gossipy comments about Ross were also inappropriate for a public academic forum.

Not long after this second intervention on the TNC list, a group of women from the list formed another discussion list called Hi-Pitched Voices (HPV), comprised primarily of hypertext writers and feminist critics. Members of HPV discussed feminist politics, shared resources, and eventually collaborated on writing projects. ${ }^{6}$ In this electronic space, the author of "Invisible Still" reflected on her electronic outburst and described what feminist electronic performances might accomplish:

What I want out of "Voices":

Collaborations. . I really want to try out the notion of virtual performance "spaces." Can we dn political art here? How do we navigate the net as women, as feminists?

(HPV, January 12, 1993)

With the small group of women signed onto HPV, she reflected directly on her experience during the "Invisible Still" exchanges as demonstrating the value of feminist intervention and role-playing in electronic spaces. These questions point to the theorizing of deliberate, performative interventions that have interested feminists (Tal, 1994; Tamblyn, 1997a). As Kali Tal (1994) explained:

\footnotetext{
${ }^{6}$ The HPV collective was founded in 1993 by writer Caroyn Guyer and the late professor Anne Johnstone. They later developed a HPV wing of Hypertext Hotel <http://www.cs.brown.edu:7000>. The project has been discussed in several articles (Greco, 1996; Guyer, Seward, \& Green, 1994; Joyce, 1995, in press). Guyer's current work, including a global collaborative writing project, Mother Millennia, can be found at <http://mothermillennia.org $>$.
} 
There are all kinds of interesting questions raised by what I call the 'performative' aspect of email (in every post you write yourself into existence for a particular audience) and lots of questions about the nature of identity politics in a disembodied/ textual space.

The "Dear Boys" and "Invisible Still" interventions were clearly performances on TNC that complicated the perception of the online community and demanded visibility for feminists as a part of the perceived audience. Feminist interventions create more than a mere forum for important voices and topics: They provide important opportunities to overtake the discursive power, to form alliances, and to lead a community to action.

\section{CONCLUSION}

In both examples of feminist software and online feminist interventions, I am advocating continued feminist presence through situated communicative practice in all forms of technology and new media. Feminists need to develop and publish software that resists the existing categories of new media, and feminists must continue to intervene in public conversations to establish a more powerful, resistant, and diverse presence within male-dominated electronic spaces. The reproductive nature of technology means that, although it reflects our political and social contexts, technology also marks an essential site for feminist struggles and a place where real power can be grasped. It is still fair to say that, until critical groundwork is accomplished on a wider scale, women online need to retain defensive and proactive postures against pervasive sexism. More importantly, feminists need to create their own audiences and involve them in the production and consumption of new technologies. The public conversations about technology need not be just conversations in a mirror.

Mary Hocks is an assistant professor of English at Georgia State University, where she also directs the Writing Across the Curriculum program. She has published articles on hypertext, gender and technology, and multimedia design. With Anne Balsamo, she serves as project director on the multimedia documentary, Women of the World Talk Back, created for the Fourth World Conference on Women in Beijing, China. Her e-mail address is<mhocks@gsu.edu>.

\section{REFERENCES}

Amnesty International [Computer software]. (1994). Berkeley, CA: Amnesty International.

Bakhtin, Mikhail M. (1986). Speech genres and other late essays (B. E. McGee, Trans); C. Emerson \& M. Holquist (Eds.). Austin, TX: University of Texas Press.

Balsamo, Anne. (1995). Technology and the gendered body: Reading cyborg women. Chapel Hill, NC: Duke University Press.

Balsamo, Anne. (in press). Notes toward a reproductive theory of technology. In E. Ann Kaplan \& Susan Squeer (Eds.), Reproductive technologies: Gender, culture, politics. New Brunswick, NJ: Rutgers University Press.

Baym, Nancy. (1995). From practice to culture on usenet. In S. L. Star (Ed.), The cultures of computing (pp. 29-52). Oxford: Basil Blackwell. 
Brail, Stephanie. (1996). The price of admission: Harassment and free speech in the wild, wild, west. In Lynn Cherny \& Elizabeth Reba Weise (Eds.), Wired women: Gender and new realities in cyberspace (pp. 141-157). Seattle, WA: Seal Press.

Greco, Diane. (1996). Hypertext with consequences: Recovering a politics of hypertext. In Hypertext '96: The seventh ACM conference on hypertext (pp. 85-92). New York: ACM.

Guyer, Carolyn; Seward, Aurelie; \& Green, Ann. (1994). Collaboration and conversation: Three voices. Computers and Composition, 11(1), 7-11.

Hacker, Sally. (1989). Pleasure, power and technology: Some tales of gender, engineering, and the cooperative workplace. Boston: Unwin Hyman.

Haraway, Donna J. (1991). Simians, cyborgs, and women: The reinvention of nature. New York: Routledge.

Harding, Sandra. (1986). The science question in feminism. Ithaca, NY: Cornell University Press.

Hocks, Mary. (in press). Designing feminist multimedia for the United Nations fourth world conference on women. In Pamela Takayoshi \& Kristine Blair (Eds.), Feminist cyberscapes: Essays on gendered academic spaces. Norward, $\mathrm{NJ}$ : Ablex.

Joyce, Michael. (1995). Of two minds: Hypertext pedagogy and poetics. Ann Arbor, MI: University of Michigan Press.

Joyce, Michael. (in press). Songs of thy selves: Persistence, momentariness, recurrence and the MOO. In Gail E. Hawisher \& Cynthia L. Selfe (Eds.), Passions, pedagogies, and 21st century technologies. Logan, UT: Utah State University Press.

Kaplan, Nancy. (1991). Ideology, technology, and the future of writing instruction. In Gail E. Hawisher \& Cynthia L. Selfe (Eds.), Evolving perspectives on computers and composition studies (pp. 7-42). Urbana, IL: National Council of Teachers of English.

Keller, Evelyn Fox. (1985). Reflections on gender and science. New Haven, CT: Yale University Press.

Kramarae, Cheris (Ed.). (1988). Technology and women's voices: Keeping in touch. New York: Routledge.

Kramarae, Cheris, \& Taylor, H. Jeanie. (1993). Women and men on electronic networks: a conversation or a monologue? In H. Jeanie Taylor, Cheris Kramarae \& Maureen Ebbon (Eds.), Women, information technology, \& scholarship (pp. 52-61). Urbana, IL: University of Illinois Center for Advanced Study.

Landow, George. (1993). Electronic conferences and Samiszdat textuality: The example of technoculture. In George Landow \& Paul Delany (Eds.), The digital word: Text-based computing (pp. 350-366). Cambridge, MA: MIT.

Martin, Emily. (1992). Body narratives, body boundaries. In Lawrence Grossberg, Cary Nelson \& Paula Treichler (Eds.), Cultural studies (pp. 409-423). New York: Routledge.

Ong, Walter S. J. (1975). The writer's audience is always a fiction. PMLA, 90, 9-21.

Perry, Ruth, \& Greber, Lisa. (1990). Women and computers: An introduction. Signs, 16(1), 74-101.

Phelps, Louise W. (1990). Audience and authorship: The disappearing boundary. In Gesa Kirsch \& Duane Roen (Eds.), A sense of audience in written communication (pp. 153-174). Newbury Park, CA: Sage.

Porter, James E. (1992). Audience and rhetoric. Prentice-Hall studies in writing and culture. Englewood Cliffs, NJ: Prentice-Hall.

Selfe, Cynthia L., \& Meyer, Paul R. (1991). Gender and electronic conferences. Written Communication, $8(2), 163-192$.

Selfe, Cynthia L., \& Selfe, Richard J., Jr. (1994). The politics of the interface: Power and its exercise in electronic contact zones. College Composition and Communication, 45, 480-504.

Sherman, Aliza. (1998). Cybergrrl! A woman's guide to the world wide web. New York: Ballantine Books. 
Spender, Dale (1995). Nattering on the net: Women, power and cyberspace. North Melbourne, Australia: Spinifex Press.

Stone, Allucquere Rosanne. (1991). Will the real body please stand up? Boundary stories about virtual cultures. In Michael Benedikt (Ed.), Cyberspace: First steps (pp. 81-118). Cambridge, MA: MIT.

Sullivan, Laura L. (1997). Cyberbabes: (Self-) Representation of women and the virtual male gaze. Computers and Composition, 14(1), 189-204.

Tal, Kali. (1994). VWAR-L as a network community. In Phil Agre, Ed. The Network Observer, 1(6). [Online, WWW]. Available: <http://dlis.gseis.ucla.edu/people/pagre/tno/june-1994.html> [October 16, 1998].

Tal, Kali. (1996). Worlds of hurt: Reading the literatures of trauma. Cambridge Studies in American Literature and Culture. Cambridge, MA: Cambridge University Press.

Tamblyn, Christine. (1997a). Remote control: the electronic transference. In Jennifer Terry \& Melodie Calvert (Eds.), Processed lives: Gender and technology in everyday life (pp. 41-46). New York: Routledge.

Tamblyn, Christine. (1997b). She likes it, she likes it not: Women and technology. In Jennifer Terry \& Melodie Calvert (Eds.), Processed lives: Gender and technology in everyday life (pp. 4750). New York: Routledge.

Terry, Jennifer, \& Calvert, Melodie. (1997). Introduction: Machines/lives. In Jennifer Terry and Melodie Calverl (Eds.), Processed lives: Gender and technology in everyday life (pp. 1-19). New York: Routledge.

Wajcman, Judy. (1991). Feminism confronts technology. University Park, PA: Pennsylvania State University Press.

Wakeford, Nina. (1997). Networking women and grrls with information/communication technology. In Jennifer Terry \& Melodie Calvert (Eds.), Processed lives: Gender and technology in everyday life (pp. 51-66). New York: Routledge. 